\section{Multi-Model Ensemble Analysis of Runoff Extremes for Climate Change Impact Assessments}

\author{
Mohammad Reza Najafi and Hamid Moradkhani ${ }^{1}$ \\ Department of Civil and Environmental Engineering, Portland State University \\ ${ }^{1}$ Corresponding Author \\ hamidm@pdx.edu
}

\title{
Abstract
}

In this study multi-model ensemble analysis of extreme runoff is performed based on eight regional climate models (RCMs) provided by the North American Regional Climate Change Assessment Program (NARCCAP). Hydrologic simulation is performed by driving the

3 Variable Infiltration Capacity (VIC) model over the Pacific Northwest region, for historical 4 and future time periods. Extreme event analysis is then conducted using spatial 5 hierarchical Bayesian modeling (SHB). Ensemble merging of extreme runoff is carried out 6 using Bayesian Model Averaging (BMA) in which spatially distributed weights corresponding to each regional climate model are obtained. Comparison of the residuals before and after the multi-model combination shows that the merged signal generally outperforms the best individual signal. The climate model simulations show close performance regarding maximum and minimum temperature and wind speed, however, the differences are more pronounced for precipitation and runoff. Between-model variances increase for the future time series compared to the historical ones indicating larger uncertainties in climate change projections. The combined model is then used to predict projected seasonal runoff extremes and compare them with historical simulations. Ensemble average results suggest that seasonal extreme runoff will increase in most regions in particular the Rockies and west of the Cascades. 


\section{Introduction}

29 Extensive global climate model (GCM) simulations have been conducted in recent years

30 including the Coupled Model Intercomparison Project-Phase 3 (CMIP3) with a coordinated

31 set of global coupled climate model experiments which are also assessed in the

32 Intergovernmental Panel on Climate Change fourth assessment report (Meehl et al., 2007).

33 Additionally CMIP5 experiments, incorporating about 20 modeling groups, are another

34 continued effort for multi-model intercomparision and analysis (Najafi et al., in press;

35 Taylor et al., 2012). These experiments are based on pre-defined scenarios of projected

36 greenhouse gas and air pollutant emissions and land use, such as the representative

37 concentration pathways (RCPs) corresponding to CMIP5 and the special report on emission

38 scenarios (SRES) in CMIP3, which are carried out in order to assess changes in the oceanic-

39 atmospheric quantities.

40 Aside from a plethora of statistical downscaling approaches currently available (Najafi et

41 al., 2011c; Wood et al., 2004), several regional-scale programs have been established in

42 order to meet the increasing demand for finer spatio-temporal resolution climate datasets.

43 These include the Prediction of Regional scenarios and Uncertainties for Defining

44 EuropeaN Climate change risks and Effects (PRUDENCE) project (Christensen and

45 Christensen, 2007), followed by the Ensembles-Based Predictions of Climate Changes and

46 Their Impacts (ENSEMBLES) project (Van der Linden and Mitchell, 2009) which provides

47 suite of regional datasets representing projected climate variations; the STAtistical and

48 Regional dynamical Downscaling of EXtremes for European regions (STARDEX) project

49 (Goodess et al., 2007); the Coordinated Regional Climate Downscaling Experiment 
50 (CORDEX) (Jones et al., 2011); and the North American Regional Climate Change

51 Assessment Program (NARCCAP) (Mearns et al., 2012).

52 These experiments are used for climate change impact assessment as well as uncertainty

53 quantification (Mearns et al., 2009). Fowler et al. (2007) combined the results of RCMs

54 from the PRUDENCE ensemble, assuming the models have equal skill. Nonparametric

55 bootstrapping was used for probabilistic estimates of extreme precipitation. Fowler and

56 Ekström (2009) further proposed a weighting scheme based on the spatial characteristics

57 and extreme precipitation statistics of the RCMs and observations. Their results indicated

58 that when all RCMs are driven by a single GCM, the model weighting does not significantly

59 impact results. Studies on combining the outputs from multiple RCMs suggest that

60 incorporating a weighting procedure based on the model performance during a training

61 period would enhance the simulation results (Casanova and Ahrens, 2009; Kug et al.,

62 2008). Multi-model ensemble studies using RCM simulations have been generally focused

63 on climate variables such as temperature (Kang et al., 2012; Smith et al., 2009; Tebaldi et

64 al., 2005) and precipitation (Fowler and Ekström, 2009; Halmstad et al., 2012; Mailhot et

65 al., 2011). Kang et al. (2012) proposed a Bayesian hierarchical model to combine winter

66 temperature from six RCMs in Phase-I of NARCCAP experiments. Zhu et al. (2012)

67 performed a Bayesian model averaging of the extreme rainfall intensities using the RCM

68 simulations provided by NARCCAP.

69 Bayesian model averaging (BMA) has gained much attention in multi-model ensemble 70 merging of hydro-climate predictions (Duan et al., 2007; Kharin and Zwiers, 2002; Najafi et

71 al., 2011a; Najafi et al., 2012; Raftery et al., 2005). BMA is a statistical technique which

72 provides weighted average of the individual models based on their performances in the 
73 training period. It considers the probability distribution function (PDF) of each model

74 simulation and provides a combined PDF based on the optimized weights and variances

75 assigned to each model. This method has been successfully applied to various hydro-

76 climatic quantities including regional weather forecast of surface temperature and sea level

77 pressure (Raftery et al., 2005), runoff (Duan et al., 2007; Najafi et al., 2011b), precipitation

78 and wind forecasting (Sloughter et al., 2010; Sloughter et al., 2007; Zhu et al., 2012) as well

79 as the humidity field (Yang and Wang, 2012). Further enhancements of ensemble

80 combination by merging data assimilation techniques (Moradkhani et al., 2012;

81 Moradkhani et al., 2005) with BMA was introduced by Parrish et al. (2012). The success of

82 Bayesian model combination has motivated this study to conduct multi-model ensemble

83 merging of runoff extremes, as obtained from a hydrologic model driven by different RCMs,

84 using this probabilistic approach.

85 This study is performed over the Pacific Northwest (PNW) (as shown in Figure 1 of Najafi 86 and Moradkhani, 2013b) which covers the Columbia River Basin (CRB). Winter (October-

87 March) precipitation dominates the hydrologic characteristics of PNW (Miles et al., 2000).

88 Precipitation in the mountains is higher especially on the western slopes of the Olympics,

89 Coast mountain range and the Cascades. The region is climatically divided by the Cascade

90 Mountains. Low elevation regions west of the Cascades are largely rain dominated while

91 the regions located on the east are snow dominated.

92 Outputs from eight downscaled RCMs were used to force the VIC hydrologic model (Liang

93 et al., 1994) followed by hierarchical Bayesian modeling of extreme runoffs (Najafi and

94 Moradkhani, 2013a; Najafi and Moradkhani, 2013b). In this study Bayesian averaging of

95 precipitation, temperature, wind speed, and runoff time series is separately conducted. 
96 Spatially distributed BMA weights corresponding to each RCM are obtained, and the

97 uncertainties related to the historical and projected runs are quantified.

98 In Section 2 of the paper a discussion of the NARCCAP datasets and the corresponding

99 regional climate models is provided along with an introduction to the observational data. In

100 Section 3 the steps for ensemble modeling of runoff extremes are explained including a

101 brief introduction to the downscaling approach, the VIC hydrologic model, spatial

102 hierarchical Bayesian modeling of extremes, and Bayesian model averaging. Section 4

103 provides the results of the model combination followed by a summary of the study along

104 with the concluding remarks in Section 5.

\section{2. Regional Climate Models}

106 The North American Regional Climate Change Assessment Program (NARCCAP)

107 (Mearns et al., 2012; Mearns et al., 2009) comprises several regional climate models

108 (RCMs). It aims at producing higher resolution datasets for climate change impact

109 assessments and uncertainty quantification. RCMs generally have varying dynamical

110 formulations and physical parameterizations including different sub-grid scale turbulence,

111 radiative transport, boundary layer effects and moist processes. NARCCAP experiments are

112 performed over similar spatio-temporal domains, which include the United States, Canada

113 and Northern Mexico. Phase-I of the experiments which are conducted over the time period

114 of 1979-2004, are based on the National Center for Environmental Prediction (NCEP-2)

115 reanalysis boundary conditions and are taken as substitute for observations. The lateral

116 boundary conditions include energy, moisture and momentum fluxes. In the second phase

117 of the experiments, fully coupled global climate models replaced the NCEP reanalysis. 
118 Simulations are performed in 50-km horizontal resolution, over the periods of 1971-2000

119 and 2041-2070 based on the SRES A2 emission scenario. In this scenario the $\mathrm{CO}_{2}$

120 concentration is expected to reach 575 and $870 \mathrm{ppm}$ (parts per million) by the middle and

121 the end of the $21^{\text {st }}$ century.

122 NARCCAP includes six RCMs (CRCM, ECP2, HRM3_ MM5I, RCM3, and WRFG) that are

123 driven by four GCMs including the Canadian Global Climate Model version 3

124 (CGCM3, (Flato, 2005)), the NCAR Community Climate Model version 3 (CCSM3, (Collins et

125 al., 2006)), the Geophysical Fluid Dynamics Laboratory (GFDL) Climate Model version 2.1

126 (CM2.1, (Anderson et al., 2004)), and the United Kingdom (UK) Hadley Centre Climate

127 Model version 3 (HadCM3, (Gordon et al., 2000)). Each RCM is nested within different

128 GCMs resulting in suite of RCM-GCM simulations. In this study data from eight RCM_GCM

129 combinations, which were available at the time these analyses were performed, are

130 considered including CRCM_cgcm3, CRCM_ccsm, HRM3_gfdl, HRM3_hadcm3, RCM3_gfdl,

131 RCM3_cgcm3, WRFG_cgcm3 and WRFG_ccsm.

132 RCMs provide hydro-climatic simulations at 3-hourly as well as daily time series at each

$13350 \mathrm{~km}$ grid cell. Daily precipitation ( $\mathrm{mm} /$ day), daily maximum and minimum temperature

$134(\mathrm{~K})$ as well as zonal and meridional wind speeds $(\mathrm{m} / \mathrm{s})$, were used to drive VIC.

135 The observed climatological fields were taken from the retrospective analysis of (Maurer 136 et al., 2002). These daily datasets are mostly calculated values based on other observations

137 rather than direct measurements. These datasets consist of $1 / 8^{\circ}$ gridded precipitation,

138 temperature and wind time series covering the period of January 1949 until July 2000. 
139 It should be noted that there are systematic biases within RCM outputs for several reasons

140 including the lateral boundary forcing and the model structures. In this study bias

141 correction was performed at the resolution of the observational data based on the quantile

142 mapping approach. For the individual months the cumulative distribution functions (CDFs)

143 of each $1 / 8^{\circ}$ cell and the closest RCM grid were matched over the historical period of 1971-

144 2000. The changes at each quantile were then applied on the future CDFs of the

145 corresponding RCM grid cell. In this approach, the RCM biases are assumed to be stationary

146 in time, implying that they remain constant for the historical and projected simulations.

147 This assumption is one of the limitations of the statistical downscaling methods.

\section{3. Methodology}

149 Using the $1 / 8^{\circ}$ observed climatological data as well as downscaled NARCCAP

150 simulations the VIC hydrologic model was driven. VIC estimates snow accumulation and

151 melt, soil moisture, evapotranspiration, surface runoff as well as baseflow. Modeling is

152 performed at a daily time step for the historical time period of 1971-2000 and future

153 period of 2041-2070 by considering three layers of soil. Five elevation bands are

154 considered to better characterize the snow processes at each grid cell. Simulations are

155 made based on the water balance equations assuming that the surface temperature is equal

156 to the surrounding air temperature. The resulting runoff $(\mathrm{mm})$ at each cell is considered for

157 the hydrologic extreme analysis. The model has been calibrated and validated by Maurer et

158 al. (2002) and similar model parameters are used in this study. Further information on

159 hydrologic modeling and extreme analysis (as briefly discussed below) is provided in

160 (Najafi and Moradkhani, 2013a; Najafi and Moradkhani, 2013b). 


\subsection{Runoff Extreme Analysis based on Hierarchical Bayesian Modeling}

163 (Coles, 2001). The generalized extreme value distribution (GEV) was used to represent the

164 seasonal maximum runoffs. GEV is defined as:

$F(y \mid \mu, \sigma, \kappa)=\exp \left\{-\left[1+\kappa\left(\frac{y-\mu}{\sigma}\right)\right]^{-1 / \kappa}\right\}$,

166 where $\mu, \sigma$ and $\kappa$ are the location, scale and shape parameters respectively and

$1671+\kappa(y-\mu) / \sigma>0$.

168 The $\tau$-year return level extreme event can be obtained from:

169

$z_{\tau}=\mu-\frac{\sigma}{\kappa}\left[1-(-\log (1-1 / \tau))^{-\kappa}\right]$

170 Spatial hierarchical Bayesian models were recently proposed to combine rare extreme data

171 from different locations in order to increase sample size and produce more reliable

172 estimates (Cooley et al., 2007; Sang and Gelfand, 2009; Schliep et al., 2010).

173 The hierarchical model is based on a likelihood function which depends on time and space:

$174 p_{1}\left(y_{i} \mid \mu_{i}, \sigma_{i}, \kappa_{i}\right)=\prod_{i=1}^{S} \prod_{t=1}^{T} \frac{1}{\sigma_{i}}\left[1+\kappa_{i}\left(\frac{y_{i t}-\mu_{i}}{\sigma_{i}}\right)\right]^{-1 / \kappa_{i}-1} \times \exp \left\{-\left[1+\kappa_{i}\left(\frac{y_{i t}-\mu_{i}}{\sigma_{i}}\right)\right]^{-1 / \kappa_{i}}\right\}$

$175 y_{i, t}$ is the annual maximum runoff at cell $i$ in time $t$. T is the total number of years for each of

176 the historical and future periods and $S$ the total number of cells. To characterize

177 uncertainties in model parameters, it is assumed that each GEV parameter follows a normal

178 distribution rather than constant values (Banerjee et al., 2004; Cooley and Sain, 2010): 
$179 p_{2}\left(\theta_{i} \mid \lambda_{\theta}, U_{i, \theta}, \tau_{\theta}^{2}\right)=N\left(X_{i, q}^{\prime} \lambda_{\theta, q}+U_{i, \theta}, 1 / \tau_{\theta}^{2}\right)$

180 where $X_{i, q}^{\prime}$ and $\lambda_{\theta, q}$ with $\theta \sim \mu, \sigma, \kappa$ represent the covariates (i.e. explanatory variables

181 such as the geographic coordinates, physical and hydro-climatologic characteristics that

182 are associated with each cell) and their corresponding factors respectively; $\tau_{\theta}^{2}$ is the

183 precision parameter (inverse of the variance). $U_{i, \theta}$ represents the spatial random effect

184 parameters and accounts for the dependencies between GEV parameters. i denotes each

185 grid cell, $q$ the number of covariates and q' the number of their associated factors $\left(q^{\prime}=\right.$ $186 \mathrm{q}+1$ ). The procedure for spatial hierarchical Bayesian modeling of runoff extremes, is

187 further illustrated in Figure 2 of Najafi and Moradkhani, 2013b.

\section{$188 \quad$ 3.2. Bayesian Model Averaging}

BMA is a probabilistic method for multi-model ensemble merging, based on post-

190 processing of deterministic models over a training period (Duan et al., 2007; Najafi et al.,

191 2011b; Raftery et al., 2005). Each ensemble member ' $m_{n}$ ' is assigned an individual

192 probability distribution function $p\left(y \mid m_{n}\right)$, which describes the probability of observing

193 hydro-climatic variable ' $y$ ' conditional on model $m_{n}$ being the best model. The posterior

194 probability of each model $m_{n}$ being correct given the measured data $O$ (i.e. $p\left(m_{n} \mid O\right)$ ) is

195 taken as the weight assigned to that model, with all weights summing to unity. The

196 resulting PDF associated with ' $y$ ' is a weighted average of each constituent PDF and can be

197 assessed based on the law of total probability: 
$198 \quad p(y)=\sum_{n=1}^{N} p\left(y \mid m_{n}, O\right) \cdot p\left(m_{n} \mid O\right)$

199 where $O$ is the observed runoff. Hydrologic variables generally follow non-Gaussian

200 distributions. In order to satisfy the Gaussian assumption the Box-Cox transformation

201 (Sakia, 1992) was applied over the simulated runoffs $\left(f_{n}\right)$ prior to BMA implementation.

202 The prior distribution $p\left(y \mid f_{n}, O\right)$ is generally assumed to be a Gaussian distribution,

$203 N\left(y \mid f_{n}, \sigma_{n}^{2}\right)$ with $f_{n}$ as the mean and $\sigma_{n}$ as the standard deviation.

204 Based on Eq. 5, the log-likelihood function is defined by:

$205 \quad l\left(w_{1}, \ldots, w_{n}, \sigma^{2}\right)=\sum_{n=1}^{N} w_{n} \cdot \sum_{t=1}^{T} N\left(y_{t}^{o b s} \mid f_{n, t}, \sigma_{n}^{\text {Iter }}\right)$

206 The Maximum Likelihood (ML) estimates of the unknown values of $p\left(f_{n} \mid O\right)$ (i.e. $\mathrm{w}_{\mathrm{n}}$ ) and $\sigma_{n}$ 207 are obtained using the iterative procedure of the EM algorithm which swaps between 208 Expectation and Maximization steps (Duan et al., 2007; McLachlan and Krishnan, 2007;

209 Raftery et al., 2005). In the Expectation step a latent variable is defined based on the 210 parameter values $\theta=w_{n}, \sigma_{n}\{n=1,2,3, \ldots, N\}$ :

$211 \hat{z}_{n, t}^{\text {ter }}=\frac{N\left(y_{t} \mid f_{n, t}, \sigma_{n}^{(\text {Iter-1) }}\right)}{\sum_{n=1}^{N} N\left(y_{t}^{o b s} \mid f_{n, t}, \sigma_{n}^{(\text {Iter }-1)}\right)}$

212 where $N\left(y_{t} \mid f_{n, t}, \sigma_{n}^{(\text {Iter-1) }}\right)$ is a normal PDF with the mean of $f_{n, t}$ and standard deviation of

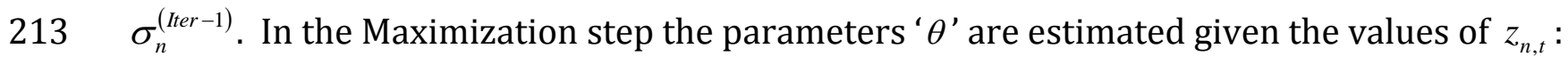


$214 \quad w_{n}^{\text {Iter }}=\frac{1}{T} \sum_{t=1}^{T} z_{n, t}^{\text {Her }}$

$215 \sigma_{n}^{2^{2 t e r}}=\frac{\sum_{t=1}^{T} \hat{z}_{n, t}^{\text {Her }} \cdot\left(y_{t}^{o b s}-f_{n, t}\right)^{2}}{\sum_{t=1}^{T} \hat{z}_{n, t}^{\text {Her }}}$

216 The convergence criterion is defined as $l\left(\theta^{\text {Iter }}\right)-l\left(\theta^{\text {Iter-1}}\right) \leq \varepsilon$ where $\varepsilon$ is the specified 217 threshold.

218 The mean and variance of BMA are obtained from:

$219 E(y \mid O)=\sum_{n=1}^{N} w_{n} f_{n}$

$220 \quad \operatorname{Var}(y \mid O)=\sum_{n=1}^{N} w_{n}\left[f_{n}-E(y \mid O)\right]^{2}+\sum_{n=1}^{N} w_{n} \sigma_{n}^{2}$

221 The variance consists of two constituents, the between model variance $\left(1^{\text {st }}\right.$ part of 222 summation in eq. 11) and the within model variance ( $2^{\text {nd }}$ part of summation). As for the 223 downscaling approach, similar stationarity assumption holds for the estimated weights.

\section{$224 \quad$ 3.3. Ensemble Merging of Extreme Runoff}

The 100-yr return level runoffs corresponding to the observed datasets and 226 different RCMs are obtained using the spatial hierarchical Bayesian model, as discussed in 227 section 3.1, which pools data from different locations and provides robust estimates of low 228 frequency extreme events (Cooley et al., 2007; Najafi and Moradkhani, 2013b). In order to merge the multi-model ensemble runs, Bayesian model averaging of 230 runoff time series is performed at individual grid cells, and the calculated BMA weights are 
231 applied on the extreme runoffs corresponding to each RCM. Similar weights in the

232 historical period are used to obtain the multi-model average results for the projected

233 extreme runoffs. The results are compared with two other scenarios: 1) Taking the

234 ensemble mean of VIC forcing signals including precipitation, temperature and wind speed

235 followed by VIC simulation and extreme value analysis, 2) Driving VIC with individual RCM

236 outputs, then combining the resulting runoffs followed by extreme analysis. In both

237 scenarios the extreme runoffs are expected to be averaged out resulting in underestimated

238 predictions. In addition averaging the inputs could affect the dependence of variables as

239 discussed in (Hanel et al., 2013; Knutti et al., 2010).

240 Spatial assessment of model performances is performed based on the estimated weights at

241 each grid cell, where better models are assigned higher weights. The between model

242 variances (and correspondingly standard deviations) are considered to represent

243 uncertainties arising from different RCMs in hydrologic impact assessments.

\section{4. Results}

245 The spatial distribution of the estimated BMA weights assigned to the downscaled daily

246 precipitation over 1971-2000 are shown in Figure 1. Although the bias correction approach

247 has significantly enhanced the simulations, results show that the simulations do not

248 perfectly match with the observation. The use of more advance bias correction

249 (postprocessing) methods by mean of copula functions can be explored in future studies

250 (Madadgar and Moradkhani, 2014). The RCM3_gfdl, CRCM_ccsm and HRM3_gfld appear to

251 receive higher weights as compared to the other RCMs. Lowest weights are assigned to

252 RCM3_cgcm3 indicating that this model has the worst performance. To the north of the 
253 Rockies, and most regions west of the Cascades higher weights are assigned to

254 HRM3_hadcm3, HRM3_gfdl and RCM3_gfdl.

255 Similar analyses were conducted for the maximum and minimum temperatures and wind

256 speed. Analysis of the maximum temperature indicates that the RCMs are almost equally

257 weighted. However, the HRM3_hadcm3 and the WRFG_ccsm are assigned slightly higher

258 weights compared to the others on the north of Rockies and west of the Cascades (not

259 shown). BMA weights obtained based on the minimum temperature values also tend to be

260 very close among the eight RCMs. The only exception is HRM3_hadcm3 which receives

261 slightly higher weights than the other RCMs. Similar results are obtained for the wind

262 speed. The weights corresponding to temperature and wind speed suggest that the RCMs

263 are performing almost equally well in estimating these variables. Therefore, the multi-

264 model average results would be similar to a strategy where all the RCMs are equally

265 weighted. This is contrary to the precipitation estimates (Figure 1) where differences

266 between model weights from various RCMs as well as the spatial variability within

267 individual RCMs are significant.

268 BMA is performed over runoff estimates from VIC hydrologic modeling based on different

269 RCMs. The assigned weights show significant spatial variability between RCMs (Figure 2).

270 The results indicate that $\mathrm{CRCM}_{-} \mathrm{ccsm}$ and $\mathrm{WRFG}_{-} \mathrm{ccsm}$ generally receive the highest

271 weights, while HRM3_hadcm3, RCM3_cgcm3 and RCM3_gfdl have the lowest values.

272 The weights assigned to each RCM can be regarded as indicators of its performance. Figure

2733 shows the $90 \%$ range of the weights for each hydro-climate quantity corresponding to

274 the individual RCMs. The average performances between the models are approximately 
275 similar regarding the maximum and minimum temperatures along with the wind speed.

276 The medians are close to 0.125 (or $1 / 8$ ) meaning that the models are almost equally

277 weighted. The differences between models are more apparent with respect to precipitation

278 and runoff estimates. This signifies the dissimilarities between regional climate models in

279 simulating precipitation and hydrologic variables such as runoff. High spatial variations

280 between the assigned weights also exist in runoff and precipitation as compared with the

281 other quantites.

282 As indicated in section 3.3 the proposed method for ensemble merging of extremes is

283 compared with two other strategies: 1) ensemble merging of climatological signals before

284 hydrologic modeling and extreme analysis and 2) ensemble merging of runoff simulations

285 before extreme analysis. Figure 4 shows the comparison between the estimated 100-yr

286 runoffs from the three model combination strategies, and the ones estimated based on the

287 observed gridded dataset as shown on the first column. Results from three strategies are

288 shown on the second to fourth columns of Figure 4 respectively. As expected the two

289 strategies in which signals are combined before extreme analysis tend to under-estimate

290 the extreme runoffs in most of the region during all seasons. However, they capture the

291 seasonal trend of extreme events showing highest extremes on the west of the Cascades

292 along with the Olympics during winter which tends to decrease by spring and summer and

293 again increase during fall. In the Rockies, where runoff is dominated by snowmelt, the

294 extreme runoffs tend to increase in spring and summer then decrease in fall and winter

295 when most of the precipitation falls and is stored as snow.

296 The biases corresponding to each model combination method are shown in Figure 5. The

297 two strategies in which Bayesian model averaging is applied before the extreme analysis 
298 provide negatively biased extreme estimates (under-estimation of the 100 -yr runoffs). The

299 biases are strong west of the Cascades and in the Rockies during spring through fall. The

300 strategy in which the obtained BMA weights are assigned to extremes shows considerably

301 lower bias.

302 The mean absolute errors of the estimated 100-yr runoffs $(\mathrm{mm})$ from the Bayesian model

303 averaging of extremes and its constituting models are compared in Table 1. The results

304 indicate that BMA outperforms the best model during the spring and summer, while it

305 outperforms most of the individual models in other seasons.

306 The between model variances are calculated for each grid cell based on Eq. 11, and the

307 corresponding standard deviations are shown for the historical (red) and future (blue)

308 time periods in Figure 6. The two peaks on the left side of each figure showing high

309 between model standard deviations correspond to the Coast Range $\left(\sim 123^{\circ} \mathrm{W}\right)$ and the

310 Cascades $\left(\sim 121^{\circ} \mathrm{W}\right)$ on the west. From Figure 6 the between model deviations

311 considerably increase over the future period especially on west of the Cascades and close

312 to the Pacific coast. This indicates an increased model uncertainty in hydrologic extreme

313 analysis for the future compared to the historical period, based on the assumption that the

314 model weights and biases are stationary in time. The spatial means of the between model

315 deviations (median of all the standard deviations for individual grid cells) increase by

316 approximately $52 \%, 80 \%, 133 \%$ and $210 \%$ during winter, spring, summer and fall

317 respectively.

318 The multi-model ensemble averages of the 100-yr return level runoffs are shown for all 319 seasons in Figure 7. The results show that in winter time extreme runoff increases in the 
320 future, in particular over the Cascades and Olympics Mountains while it decreases in

321 eastern Oregon and west of Idaho. In spring the results show future increases over the

322 Rockies, especially in the Canadian portion of the Columbia River Basin, as well as west of

323 the Cascades and the Olympics Mountains. The runoffs generally decrease in summer,

324 while showing slight increases on the west coast. Fall season will experience increased

325 extreme runoffs on west of the Cascades and the Rockies. There are slight increases in

326 almost all other grid cells as well.

327 Figure 8 compares the seasonal multi-model average 100-yr runoffs for the historical and

328 future time periods. Each circle represents a grid cell in the region with the ones above the

329 splitting line showing increases in extreme runoffs. Approximately $90 \%$ of the grid cells

330 show increased extreme runoff during winter and spring, while only $60 \%$ of the cells show

331 increases in the summer. During the fall season almost all grid cells are expected to

332 experience increased extreme runoffs. A linear regression model was fitted to the historical

333 and future time series over each season. The generated scaling factors (i.e. $\beta$ in $Y=X \beta+\alpha$ ) for

334 each season are shown in Table 2. Results show overall increases in runoff extremes in the 335 future time period.

\section{5. Summary and Conclusions}

337 Eight RCM_GCM combinations including CRCM_cgcm3, CRCM_ccsm, HRM3_gfdl, 338 HRM3_hadcm3, RCM3_gfdl, RCM3_cgcm3, WRFG_cgcm3 and WRFG_ccsm were considered 339 for the extreme ensemble merging. Analyses were based on the downscaled precipitation, 340 temperature and wind speed, the VIC hydrologic model simulations, and the spatial 
341 hierarchical Bayesian model estimates of the extreme runoff. Ensemble average results by

342 means of Bayesian model averaging were then compared to the individual estimations.

343 BMA was applied on the daily runoff simulations obtained from VIC based on different

344 RCMs. The estimated weights for all cells were applied on the predicted 100-yr runoffs

345 corresponding to individual RCMs in order to obtain the ensemble average results for both

346 the historical and future time periods. BMA performance was satisfactory as it

347 outperformed the best model during spring and summer seasons. The BMA weights were

348 spatially uniform regarding the temperature and wind speed, however, they varied

349 considerably for precipitation and runoff suggesting that there is large spatial variation in

350 RCM performances with respect to these quantities.

351 The between model variability was also quantified which showed that fall has the highest

352 variability in the future compared to its historical period.

353 Overall the multi-model results show increases in the extreme runoffs in the future in most

354 regions, particularly over the high elevations, such as the north of Rockies during spring.

355 The results also suggest that less than half of the PNW area will experience reduced

356 extreme events during summer, while extreme events are projected to increase for almost

357 the entire PNW during fall. These results suggest substantial shift in the seasonality of peak

358 stream-flow, mainly from summer to spring for several regions of the Pacific Northwest.

359 In this study the downscaling process was based on the quantile mapping approach and no

360 further adjustments for wet-day frequency or future extremes were applied. In addition

361 downscaling of the RCM_GCM variables for the future period was based on stationarity

362 assumption, that the biases between observations and simulations obtained for historical 
363 period would remain unchanged. Similar assumption was made regarding the BMA weights

364 that were applied on the projected simulations. However, models with high performance

365 skills in the historical period do not necessarily show future prediction skill (Reifen and

366 Toumi, 2009). Also Uncertainties arise due to the weighting process (Hesselbjerg

367 Christensen et al., 2010) depending on the individual model error uncertainties as well as

368 the degree of model error correlation and the relative magnitude of the unpredictable noise

369 (Weigel et al., 2010).

370 Acknowledgement:

371 Partial financial support for this project was provided by the National Science Foundation,

372 Water Sustainability and Climate (WSC) program (grant no. EAR-1038925) and the DOE-

373 BPA (cooperative agreement 00063182). The authors thank the NARCCAP for providing

374 the data used in this article. NARCCAP is funded by the National Science Foundation, the US

375 Department of Energy, the National Oceanic and Atmospheric Administration and the US

376 Environmental Protection Agency Office of Research and Development. 


\section{References}

380

Anderson, J. et al., 2004. The new GFDL global atmosphere and land model AM2-LM2: Evaluation with prescribed SST simulations. J. Climate, 17(24): 4641-4673.

Banerjee, S., Carlin, B.P., Gelfand, A.E., 2004. Hierarchical modeling and analysis for spatial data, 101. Chapman \& Hall.

Casanova, S., Ahrens, B., 2009. On the weighting of multimodel ensembles in seasonal and short-range weather forecasting. Monthly weather review, 137(11): 3811-3822.

Christensen, J.H., Christensen, O.B., 2007. A summary of the PRUDENCE model projections of changes in European climate by the end of this century. Climatic Change, 81: 7-30.

Coles, S., 2001. An introduction to statistical modeling of extreme values. Springer Verlag.

Collins, W.D. et al., 2006. The community climate system model version 3 (CCSM3). Journal of Climate, 19(11): 2122-2143.

Cooley, D., Nychka, D., Naveau, P., 2007. Bayesian spatial modeling of extreme precipitation return levels. Journal of the American Statistical Association, 102(479): 824-840.

Cooley, D., Sain, S.R., 2010. Spatial hierarchical modeling of precipitation extremes from a regional climate model. Journal of agricultural, biological, and environmental statistics, 15(3): 381-402.

Duan, Q., Ajami, N.K., Gao, X., Sorooshian, S., 2007. Multi-model ensemble hydrologic prediction using Bayesian model averaging. Advances in Water Resources, 30(5): 1371-1386.

Flato, G., 2005. The third generation coupled global climate model (CGCM3). Canadian Centre for Climate Modelling and Analysis: Canada. http://www. cccma. ec. gc. $\mathrm{ca} /$ models/cgcm3. shtml.

Fowler, H., Ekström, M., 2009. Multi-model ensemble estimates of climate change impacts on UK seasonal precipitation extremes. International Journal of Climatology, 29(3): 385-416.

Fowler, H., Ekström, M., Blenkinsop, S., Smith, A., 2007. Estimating change in extreme European precipitation using a multimodel ensemble. Journal of Geophysical Research, 112(D18): D18104.

Goodess, C. et al., 2007. An intercomparison of statistical downscaling methods for Europe and European regions-assessing their performance with respect to extreme temperature and precipitation events. Climatic Change.

Gordon, C. et al., 2000. The simulation of SST, sea ice extents and ocean heat transports in a version of the Hadley Centre coupled model without flux adjustments. Climate Dynamics, 16(2): 147-168.

Halmstad, A., Najafi, M.R., Moradkhani, H., 2012. Analysis of precipitation extremes with the assessment of regional climate models over the Willamette River Basin, USA. Hydrological Processes. 
Hanel, M., Mrkvičková, M., Máca, P., Vizina, A., Pech, P., 2013. Evaluation of simple statistical downscaling methods for monthly regional climate model simulations with respect to the estimated changes in runoff in the Czech Republic. Water resources management, 27(15): 5261-5279.

Hesselbjerg Christensen, J., Kjellström, E., Giorgi, F., Lenderink, G., Rummukainen, M., 2010. Weight assignment in regional climate models. Climate Research, 44(2-3): 179-194.

Jones, C., Giorgi, F., Asrar, G., 2011. The Coordinated Regional Downscaling Experiment: CORDEX an international downscaling link to CMIP5. CLIVAR exchanges, 16(2): 3440.

Kang, E.L., Cressie, N., Sain, S.R., 2012. Combining outputs from the North American Regional Climate Change Assessment Program by using a Bayesian hierarchical model. Journal of the Royal Statistical Society: Series C (Applied Statistics).

Kharin, V.V., Zwiers, F.W., 2002. Climate predictions with multimodel ensembles. Journal of Climate, 15(7): 793-799.

Knutti, R., Furrer, R., Tebaldi, C., Cermak, J., Meehl, G.A., 2010. Challenges in combining projections from multiple climate models. Journal of Climate, 23(10): 2739-2758.

Kug, J.-S., Lee, J.-Y., Kang, I.-S., Wang, B., Park, C.-K., 2008. Optimal multimodel ensemble method in seasonal climate prediction. Asia-Pacific J Atms Sci, 44: 233-247.

Madadgar, S., Moradkhani, H., 2014. Improved Bayesian Multi-modeling: Integration of

Mailhot, A., Beauregard, I., Talbot, G., Caya, D., Biner, S., 2011. Future changes in intense precipitation over Canada assessed from multi-model NARCCAP ensemble simulations. International Journal of Climatology.

Maurer, E., Wood, A., Adam, J., Lettenmaier, D., Nijssen, B., 2002. A Long-Term Hydrologically Based Dataset of Land Surface Fluxes and States for the Conterminous United States*. Journal of Climate, 15(22): 3237-3251.

McLachlan, G.J., Krishnan, T., 2007. The EM algorithm and extensions, 382. WileyInterscience.

Mearns, L. et al., 2012. The North American regional climate change assessment program: Overview of phase I results. Bulletin of the American Meteorological Society, 93(9): 1337-1362.

Mearns, L. et al., 2009. A regional climate change assessment program for North America. Eos Trans. AGU, 90(36): 311.

Meehl, G. et al., 2007. The WCRP CMIP3 multi-model dataset: A new era in climate change research. Bulletin of the American Meteorological Society, 88: 1383-1394.

Miles, E.L., Snover, A.K., Hamlet, A.F., Callahan, B., Fluharty, D., 2000. Pacific Northwest regional assessment: the impacts of climate variability and climate change on the water resources of the Columbia River Basin. JAWRA Journal of the American Water Resources Association, 36(2): 399-420. 
Moradkhani, H., DeChant, C.M., Sorooshian, S., 2012. Evolution of ensemble data assimilation for uncertainty quantification using the particle filter-Markov chain Monte Carlo method. Water Resources Research, 48(12).

Moradkhani, H., Hsu, K.-L., Gupta, H., Sorooshian, S., 2005. Uncertainty assessment of hydrologic model states and parameters: Sequential data assimilation using the particle filter. Water Resources Research, 41(5): W05012.

Najafi, M., Kavianpour, Z., Najafi, B., Kavianpour, M.R., Moradkhani, H., 2011a. Air demand in gated tunnels-a Bayesian approach to merge various predictions. Journal of Hydroinformatics, 14(1): 152-166.

Najafi, M., Moradkhani, H., Jung, I., 2011b. Assessing the uncertainties of hydrologic model selection in climate change impact studies. Hydrological Processes, 25(18): 28142826.

Najafi, M., Moradkhani, H., Piechota, T., 2012. Ensemble Streamflow Prediction: Climate signal weighting methods vs. Climate Forecast System Reanalysis. Journal of Hydrology, 442-443: 105-116.

Najafi, M., Zwiers, F.W., Gillett, N.P., in press. Attribution of Arctic Temperature Change to Greenhouse Gas and Aerosol Influences Nature Climate Change.

Najafi, M.R., Moradkhani, H., 2013a. Analysis of runoff extremes using spatial hierarchical Bayesian modeling. Water Resources Research, 49(10): 6656-6670.

Najafi, M.R., Moradkhani, H., 2013b. A hierarchical Bayesian approach for the analysis of climate change impact on runoff extremes. Hydrological Processes.

Najafi, M.R., Moradkhani, H., Wherry, S.A., 2011c. Statistical Downscaling of Precipitation using Machine Learning with Optimal Predictor Selection. Journal of Hydrologic Engineering, 16(8): 650-664.

Parrish, M.A., Moradkhani, H., DeChant, C.M., 2012. Toward reduction of model uncertainty: Integration of Bayesian model averaging and data assimilation. Water Resources Research, 48(3).

Raftery, A.E., Gneiting, T., Balabdaoui, F., Polakowski, M., 2005. Using Bayesian model averaging to calibrate forecast ensembles. Monthly Weather Review, 133(5): 11551174.

Reifen, C., Toumi, R., 2009. Climate projections: Past performance no guarantee of future skill? Geophysical Research Letters, 36(13).

Sakia, R., 1992. The Box-Cox transformation technique: a review. The statistician: 169-178.

Sang, H., Gelfand, A.E., 2009. Hierarchical modeling for extreme values observed over space and time. Environmental and ecological statistics, 16(3): 407-426.

Schliep, E.M., Cooley, D., Sain, S.R., Hoeting, J.A., 2010. A comparison study of extreme precipitation from six different regional climate models via spatial hierarchical modeling. Extremes, 13(2): 219-239. 
Sloughter, J.M.L., Gneiting, T., Raftery, A.E., 2010. Probabilistic wind speed forecasting using ensembles and Bayesian model averaging. Journal of the American Statistical Association, 105(489): 25-35.

Sloughter, J.M.L., Raftery, A.E., Gneiting, T., Fraley, C., 2007. Probabilistic quantitative precipitation forecasting using Bayesian model averaging. Monthly weather review, 135(9): 3209-3220.

Smith, R.L., Tebaldi, C., Nychka, D., Mearns, L.O., 2009. Bayesian modeling of uncertainty in ensembles of climate models. Journal of the American Statistical Association, 104(485): 97-116.

Taylor, K.E., Stouffer, R.J., Meehl, G.A., 2012. An overview of CMIP5 and the experiment design. Bulletin of the American Meteorological Society, 93(4): 485.

Tebaldi, C., Smith, R.L., Nychka, D., Mearns, L.0., 2005. Quantifying uncertainty in projections of regional climate change: A Bayesian approach to the analysis of multimodel ensembles. Journal of Climate, 18(10): 1524-1540.

Van der Linden, P., Mitchell, J., 2009. ENSEMBLES: Climate Change and its Impacts: Summary of research and results from the ENSEMBLES project. Met Office Hadley Centre, FitzRoy Road, Exeter EX1 3PB, UK, 160.

Weigel, A.P., Knutti, R., Liniger, M.A., Appenzeller, C., 2010. Risks of model weighting in multimodel climate projections. Journal of Climate, 23(15): 4175-4191.

Wood, A.W., Leung, L.R., Sridhar, V., Lettenmaier, D., 2004. Hydrologic implications of dynamical and statistical approaches to downscaling climate model outputs. Climatic Change, 62(1): 189-216.

Yang, H., Wang, B., 2012. Reducing biases in regional climate downscaling by applying Bayesian model averaging on large-scale forcing. Climate Dynamics: 1-10.

Zhu, J., Forsee, W., Schumer, R., Gautam, M., 2012. Future projections and uncertainty assessment of extreme rainfall intensity in the United States from an ensemble of climate models. Climatic Change: 1-17. 


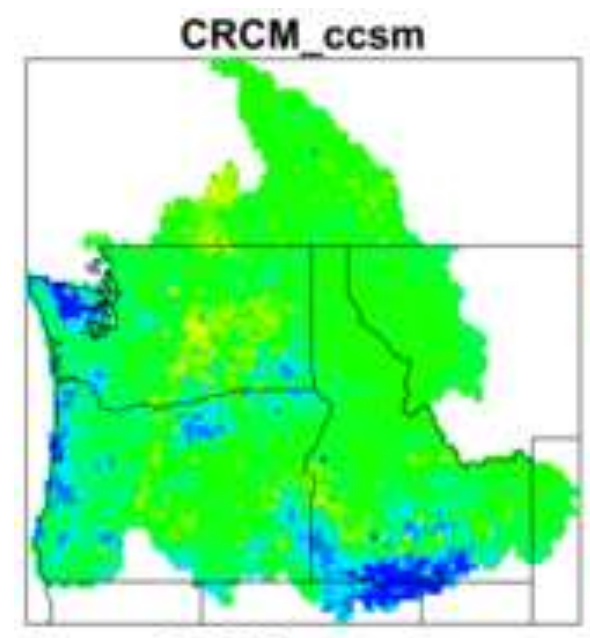

RCM3_cgcm3

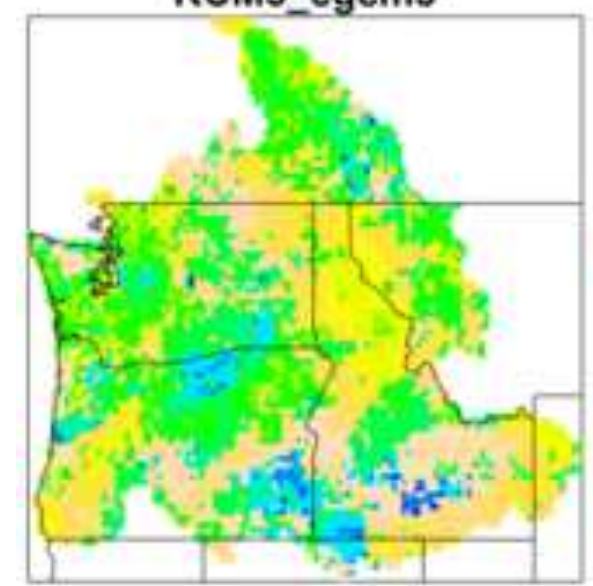

CRCM_cgcm 3

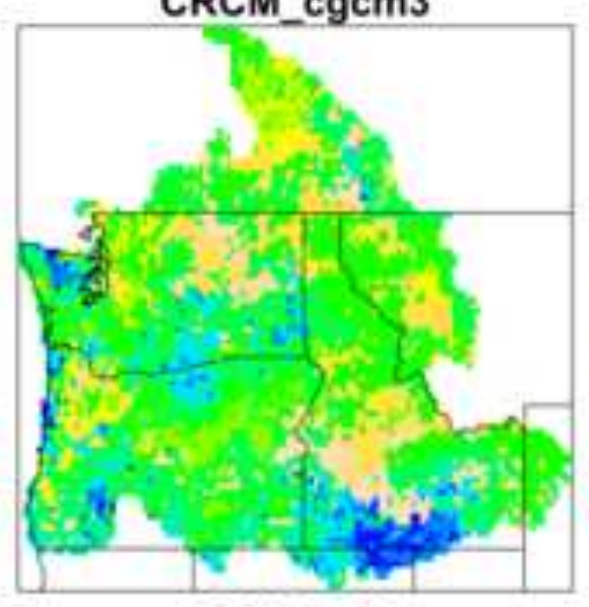

RCM3_gfdi

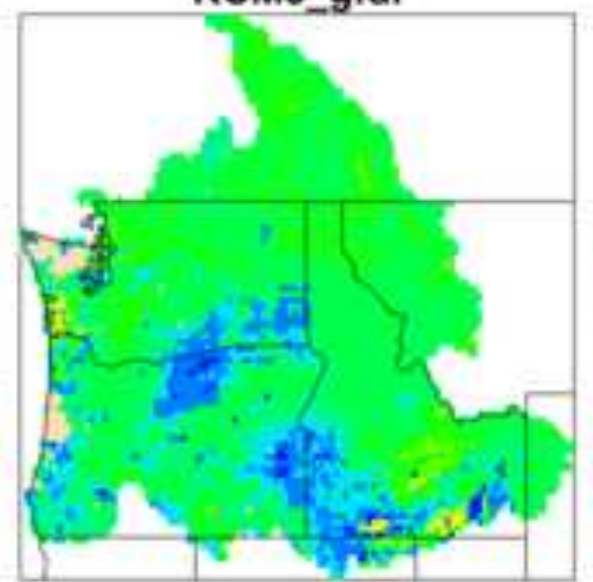

HRM3_gfdl

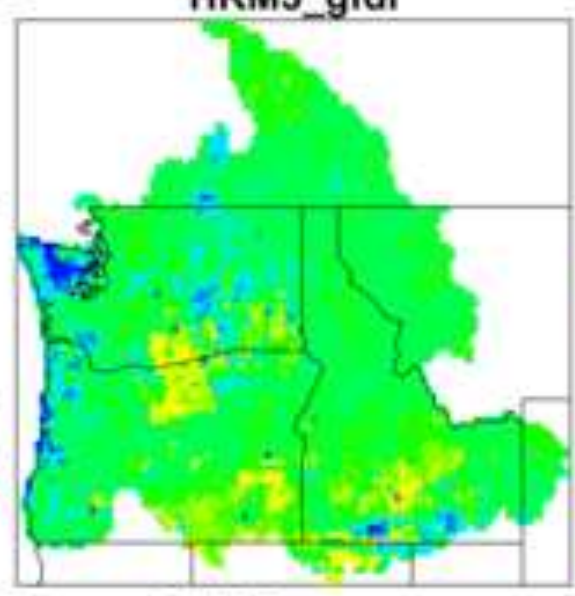

WRFG_ccsm

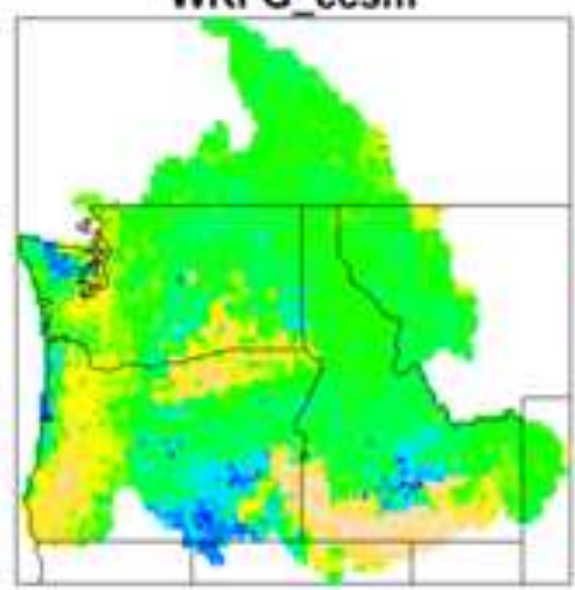

HRM 3 hadcm 3

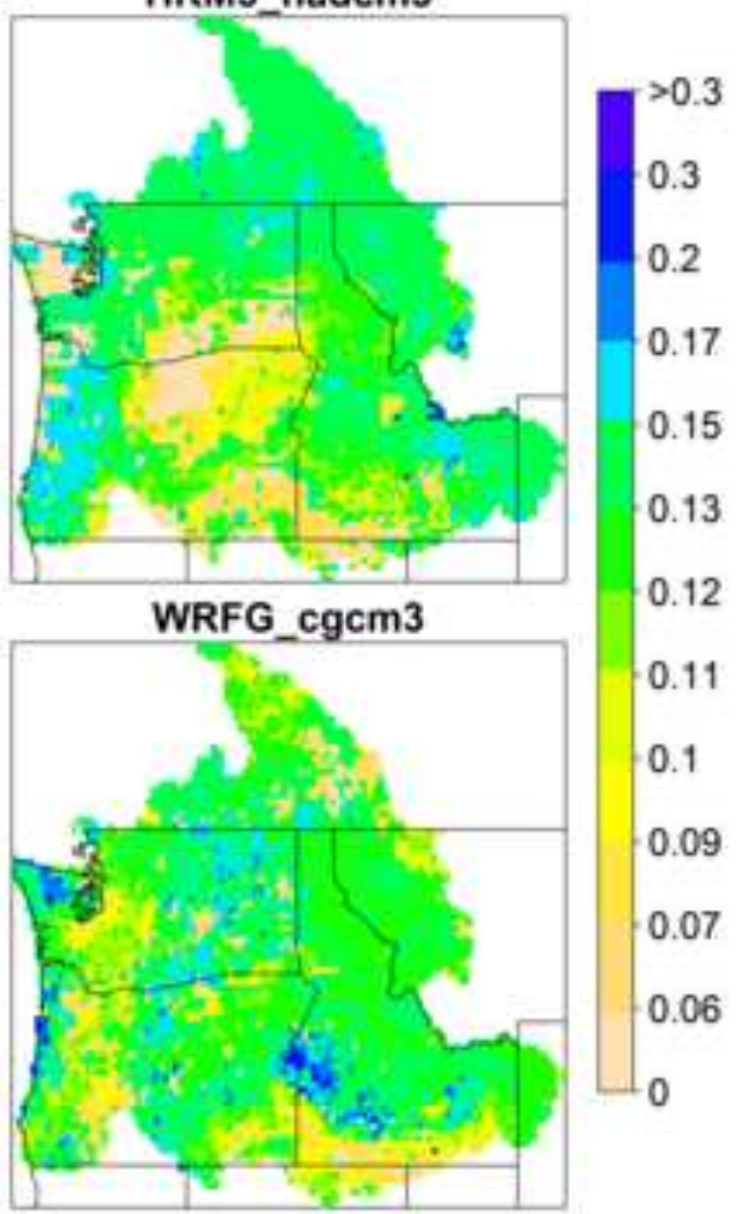



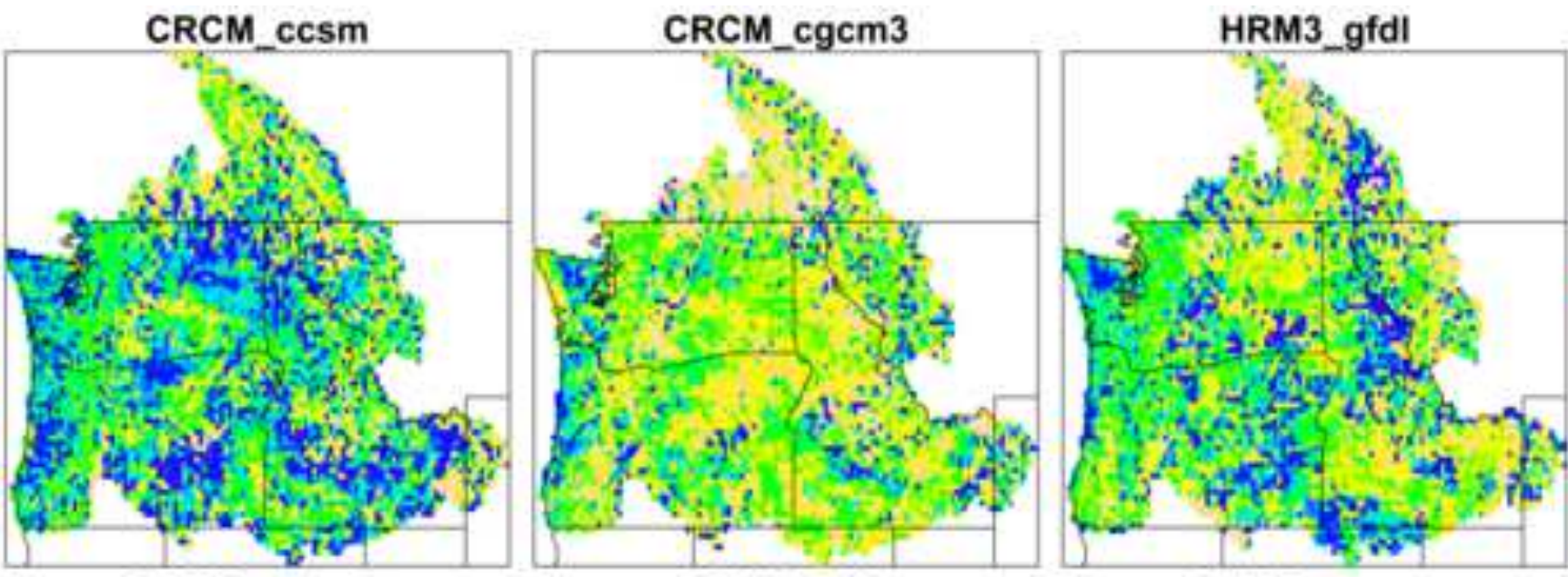

RCM3_cgcm3

RCM3_gfdi

WRFG_ccsm
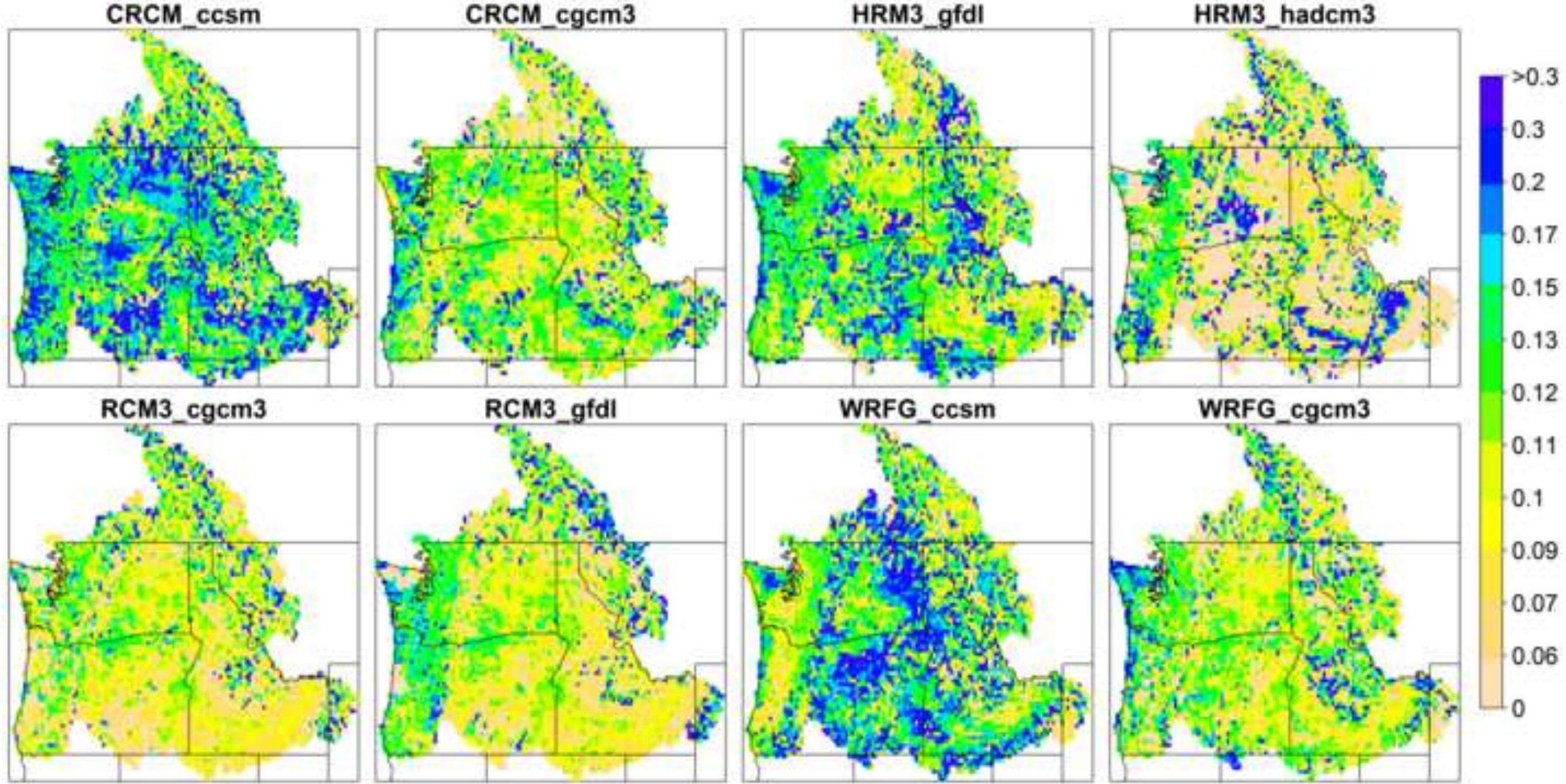


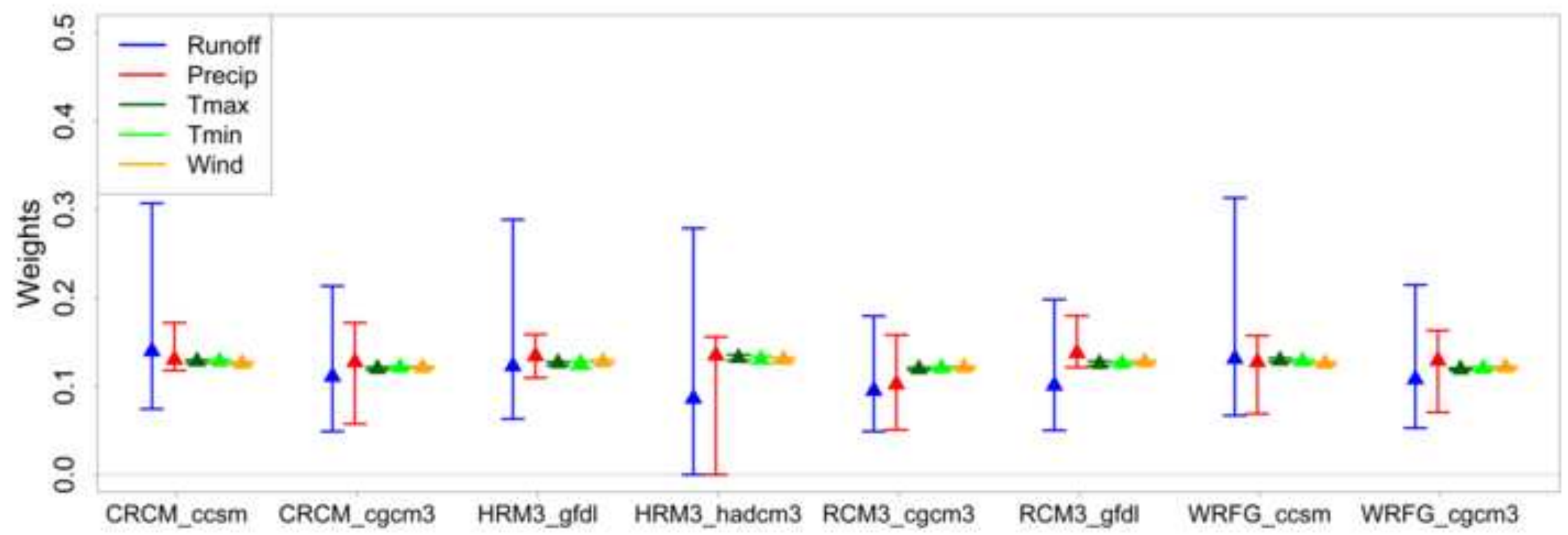



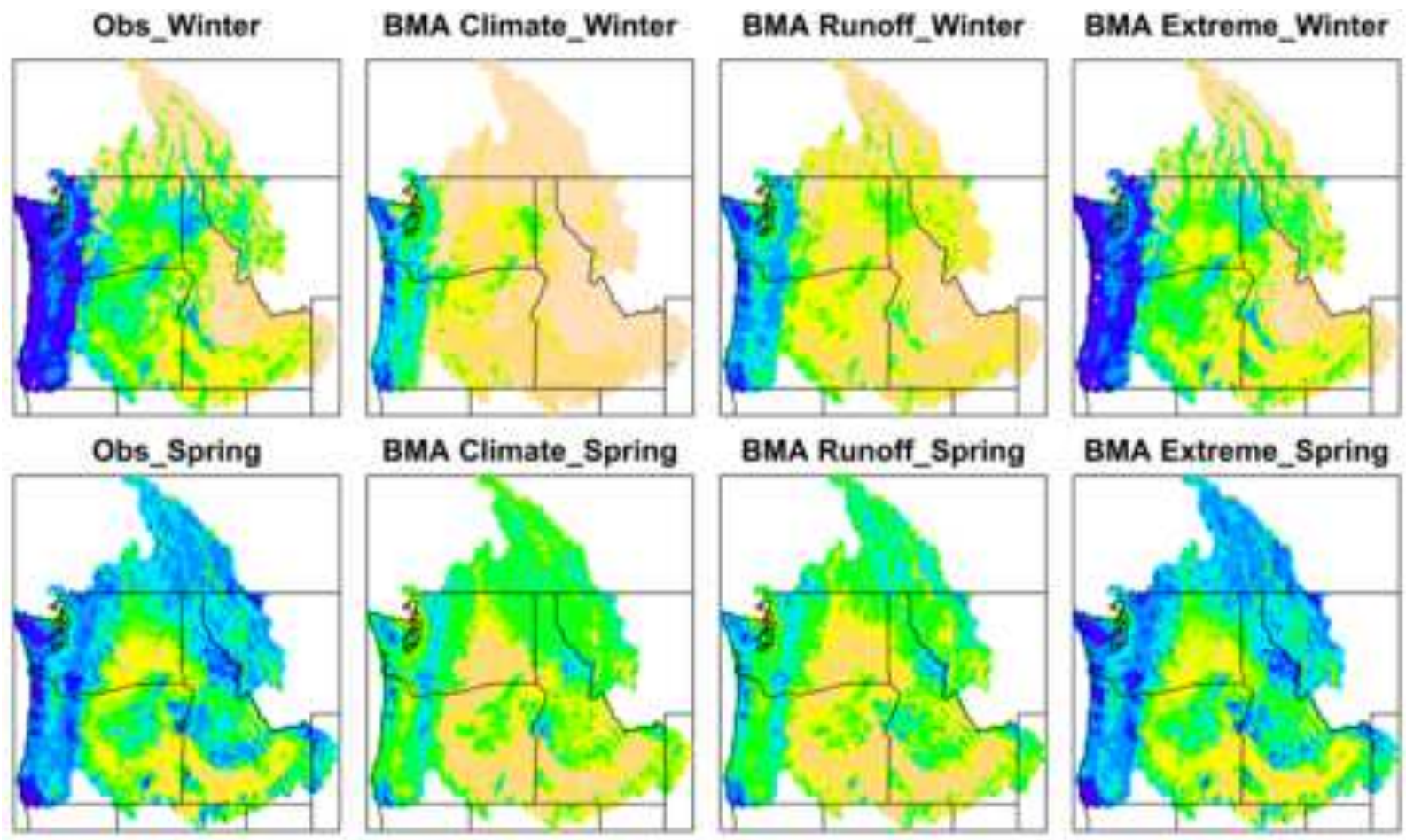

BMA Extreme_Winter

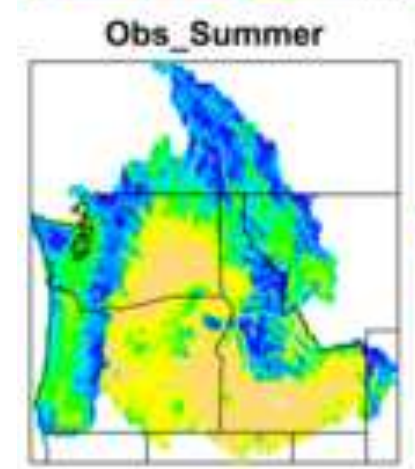

BMA Climate_Summer
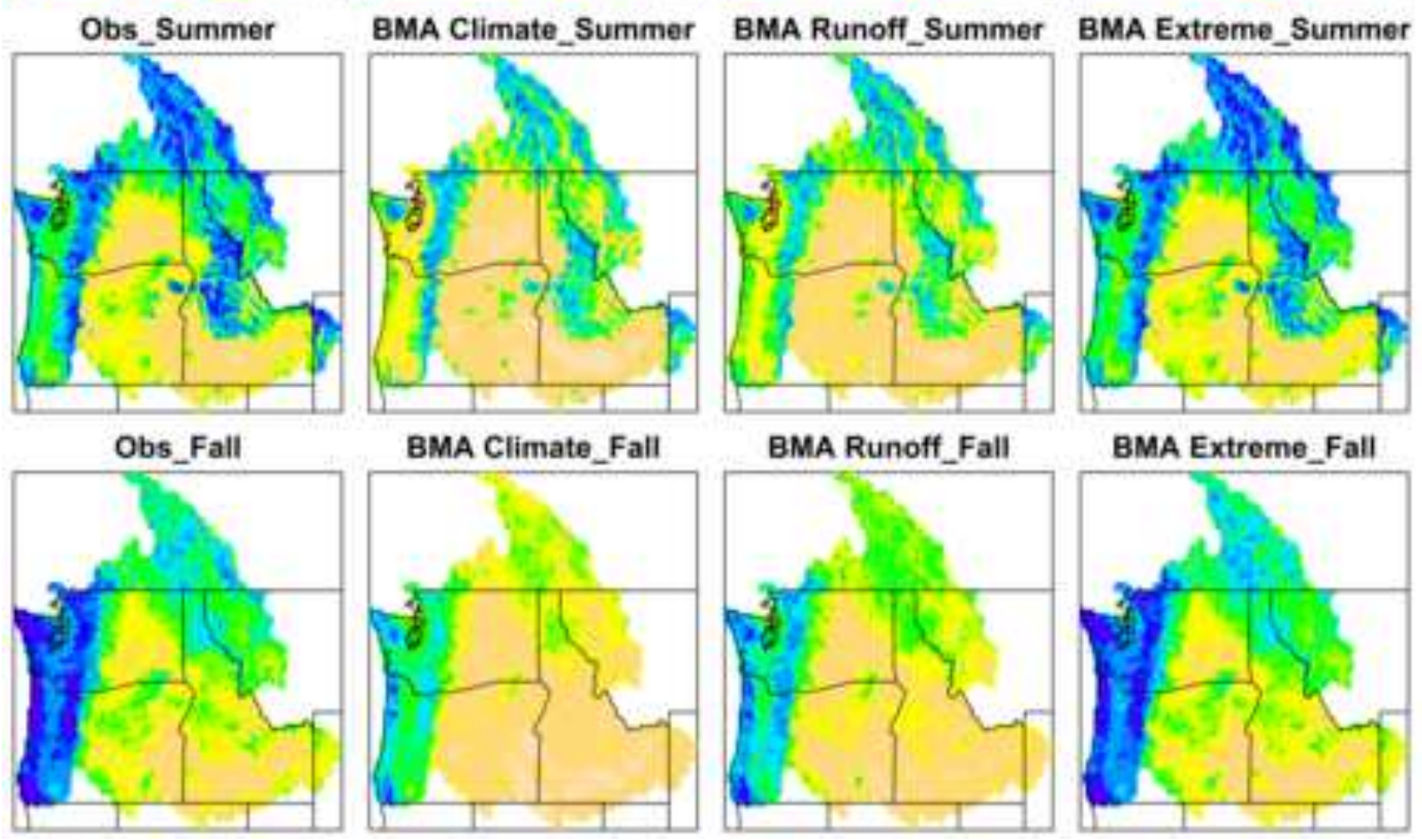

$-6.5$

$-4.5$

3

$-2$
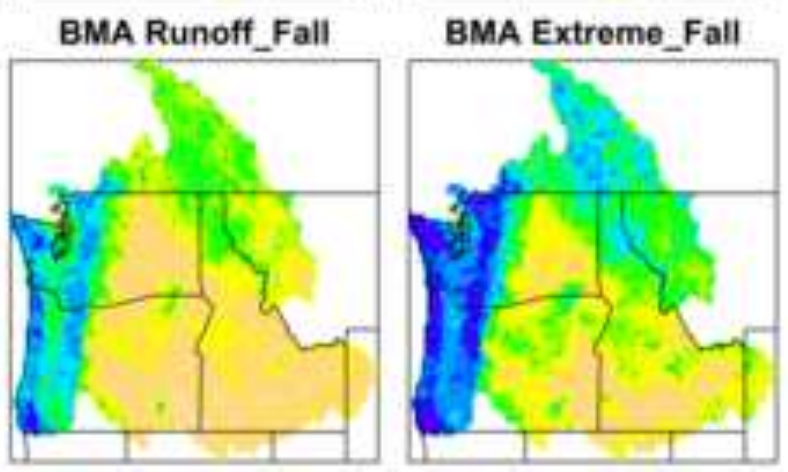

$-1.5$

$-0.2$ 
BMA Climate_Winter

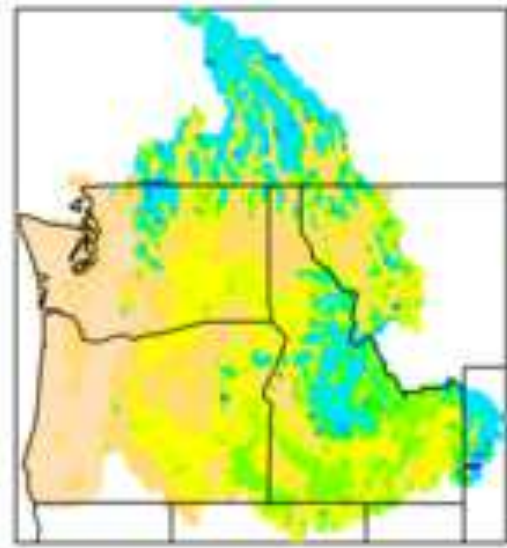

BMA Climate_Spring

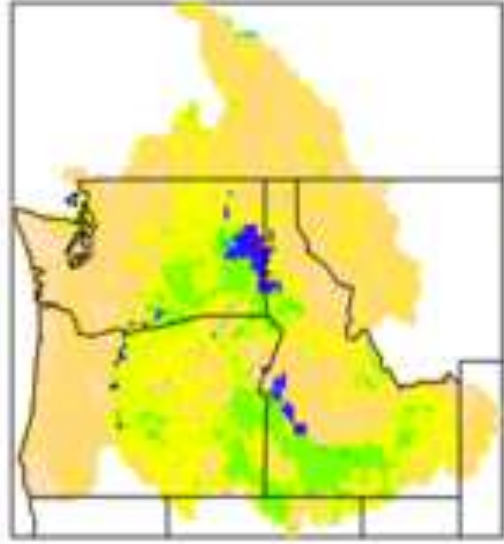

BMA Climate_Summer
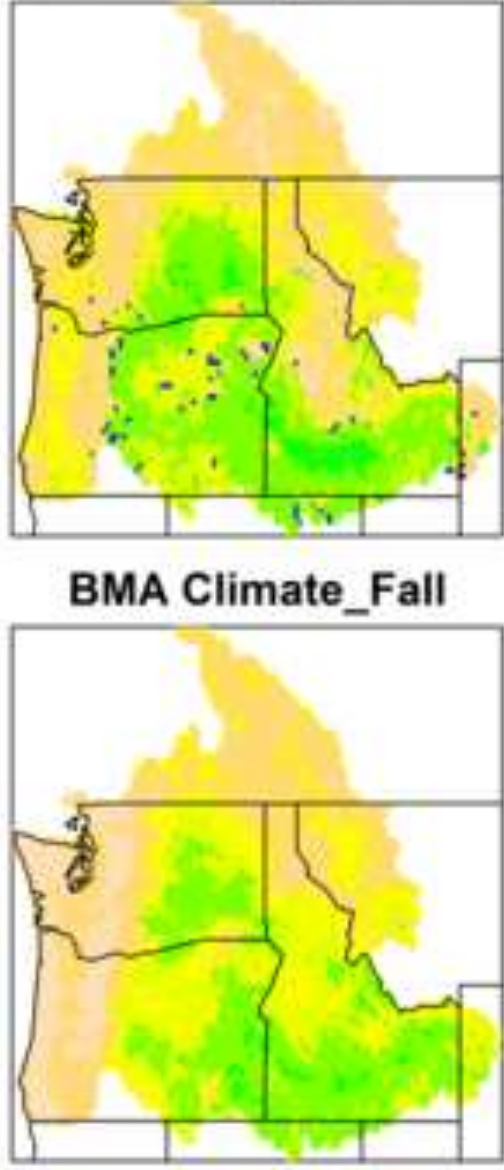

BMA Runoff_Winter

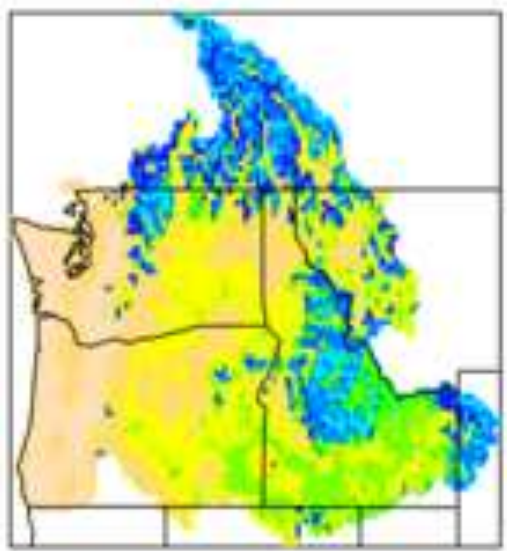

BMA Runoff_Spring

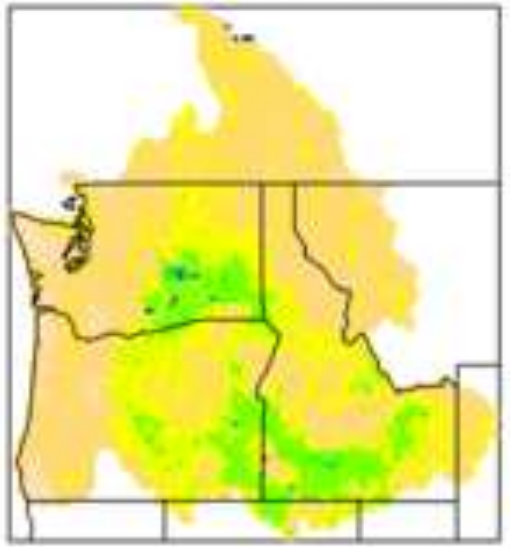

BMA Runoff_Summer
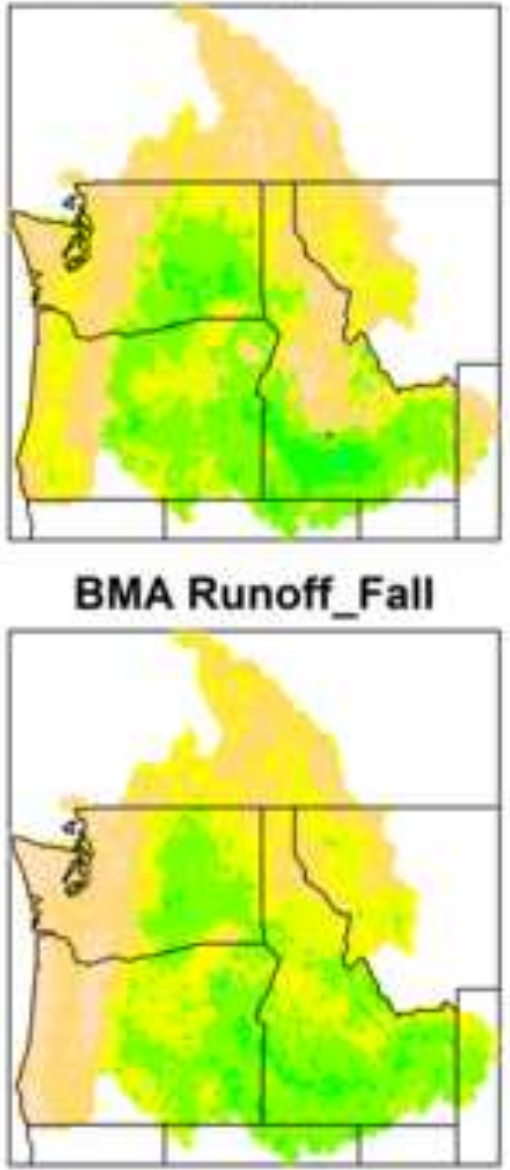

BMA Extreme_Winter

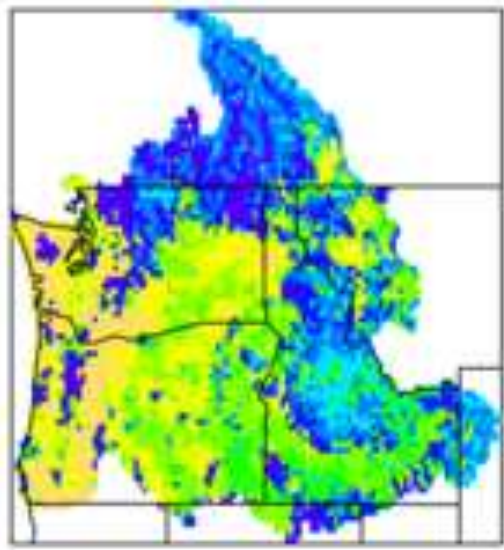

1.5

0.5

BMA Climate_Spring

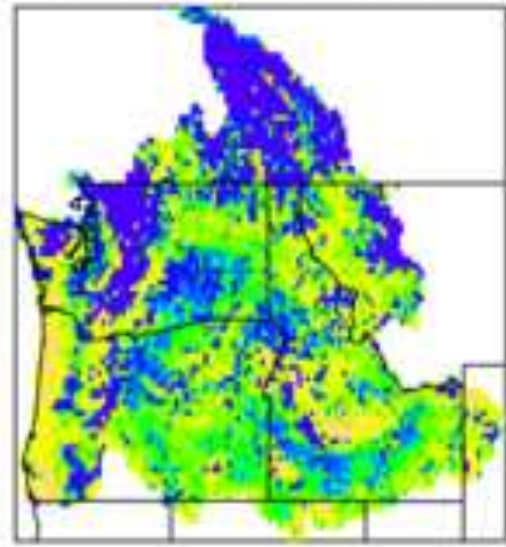

0

$-0.05$

$-0.1$

$-0.5$

BMA Climate_Summer

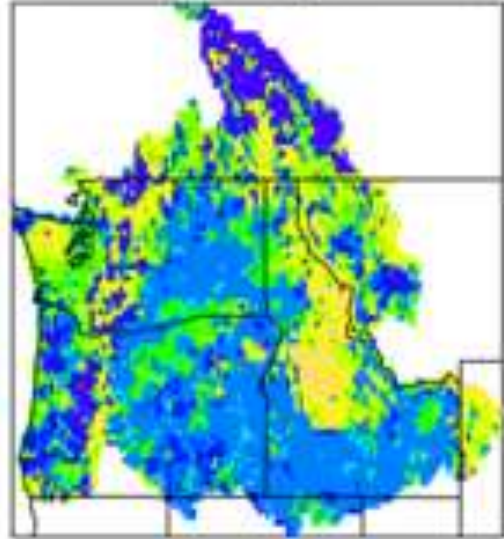

$-2$

$-4$

$--7$

$-10$

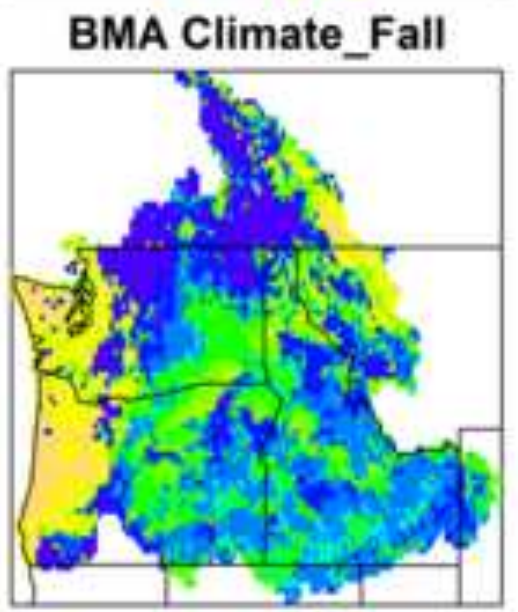



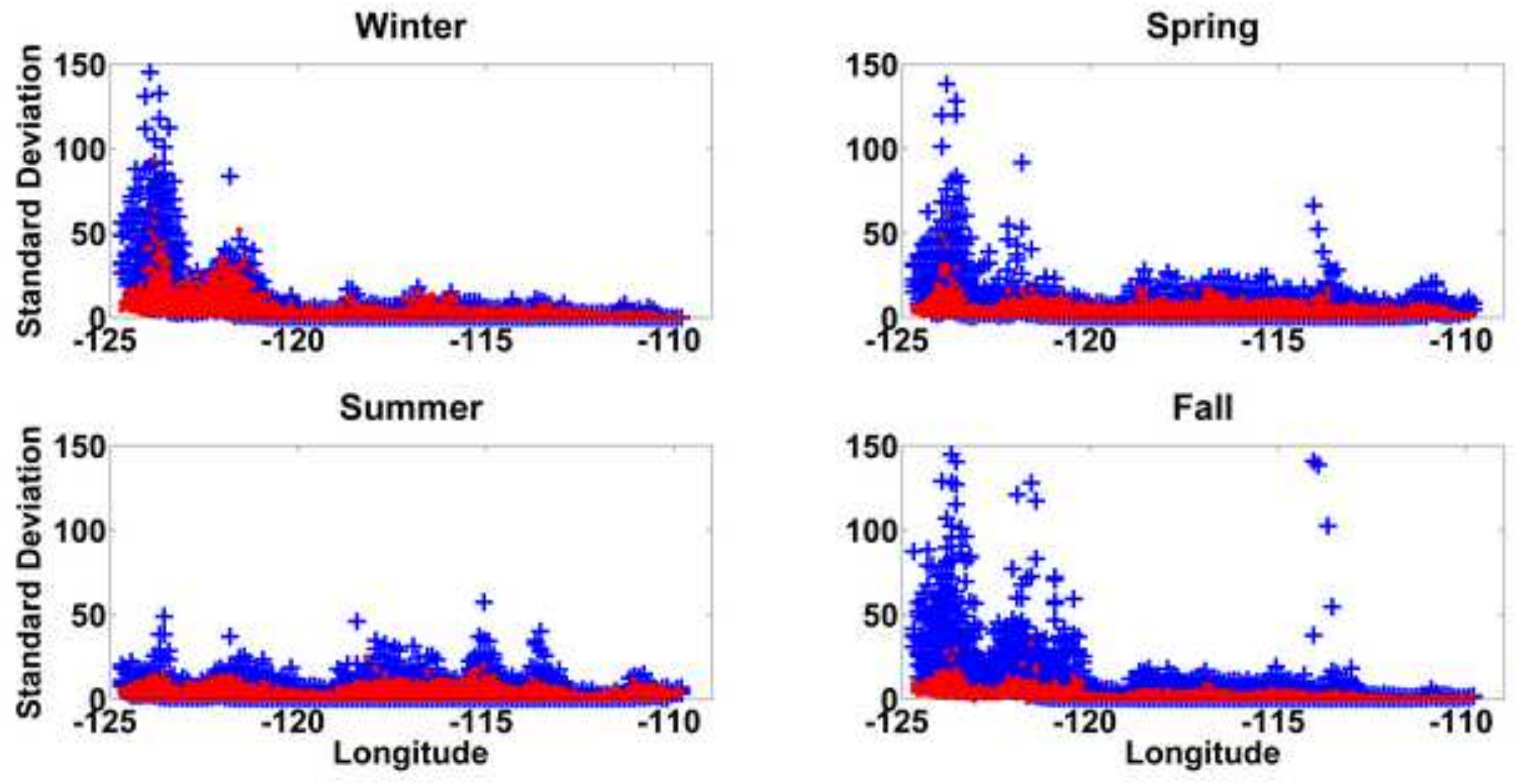


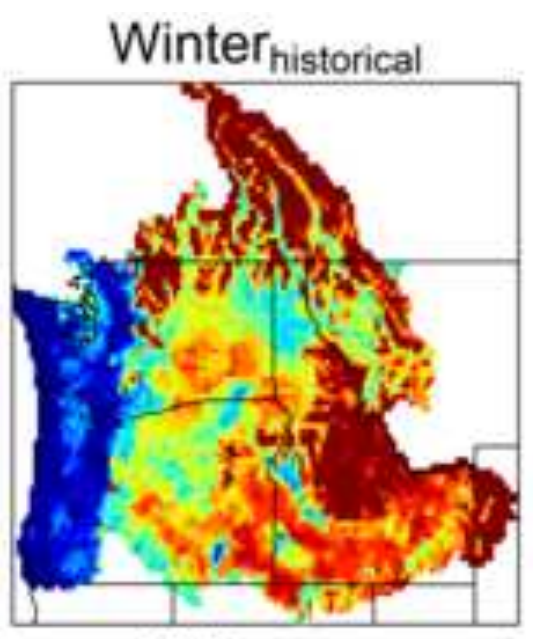

Winter future $_{\text {fur }}$

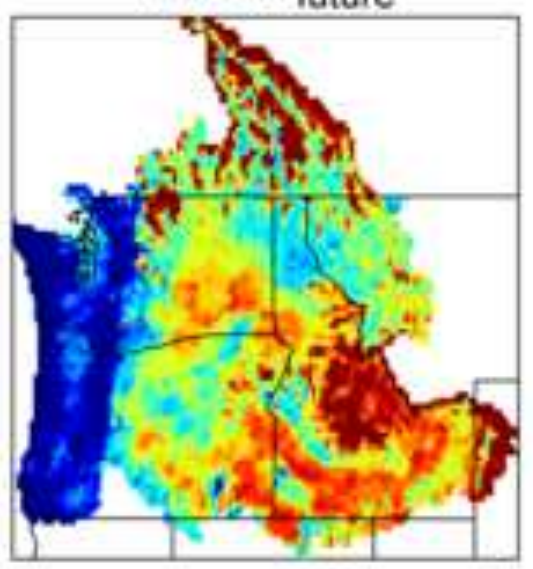

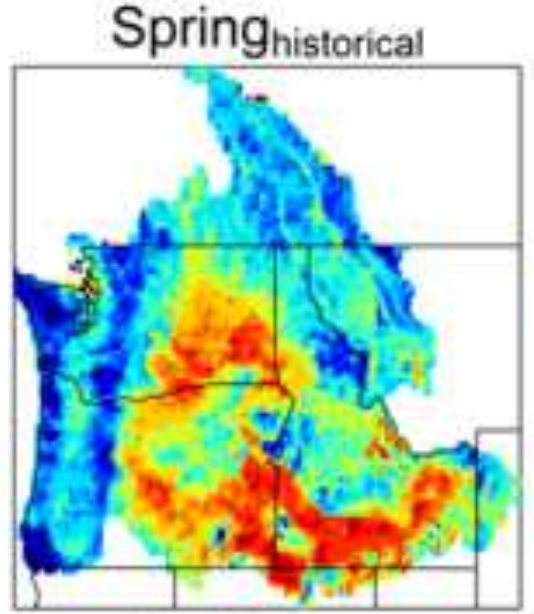

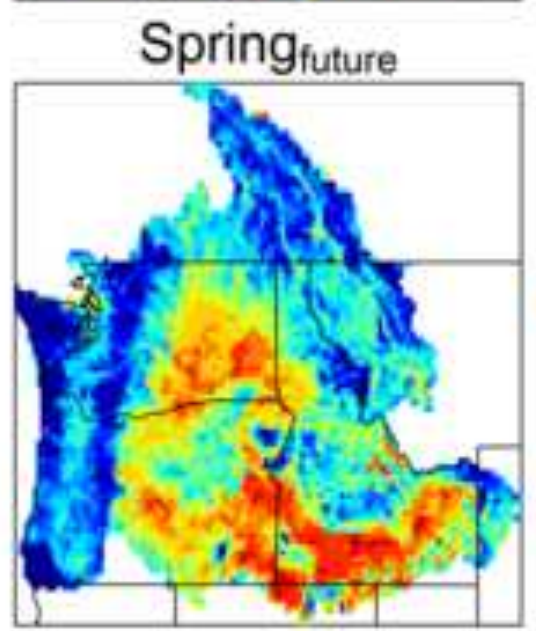

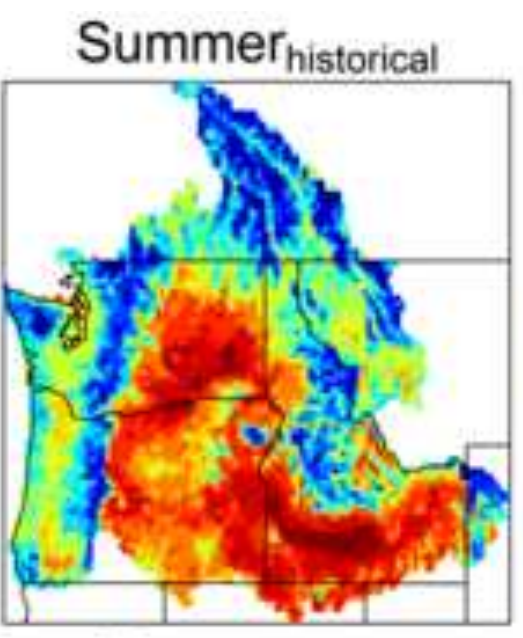

Summer future

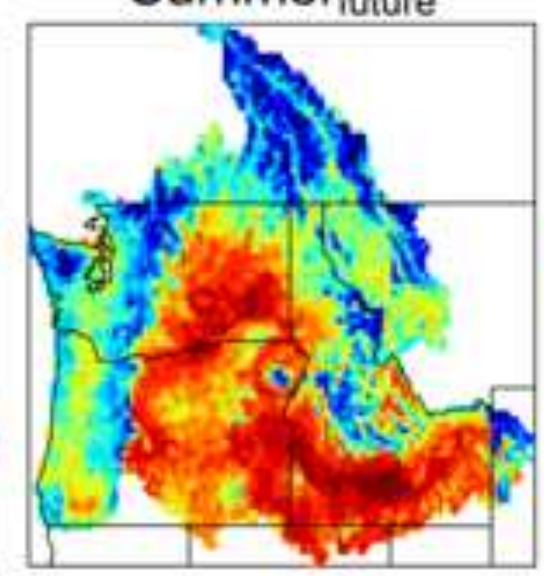

Fall $_{\text {historical }}$

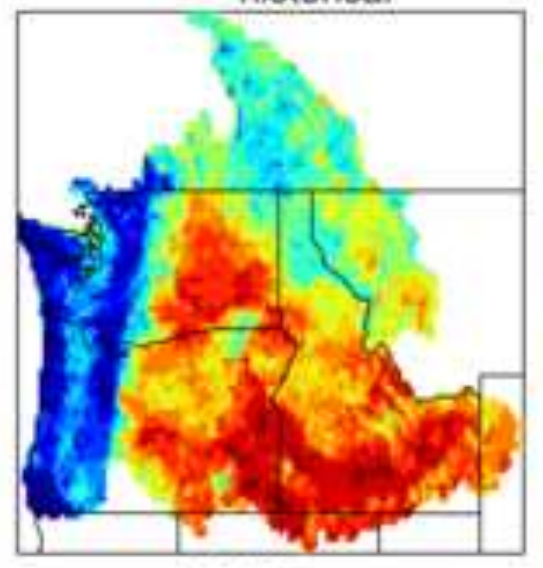

Fall future

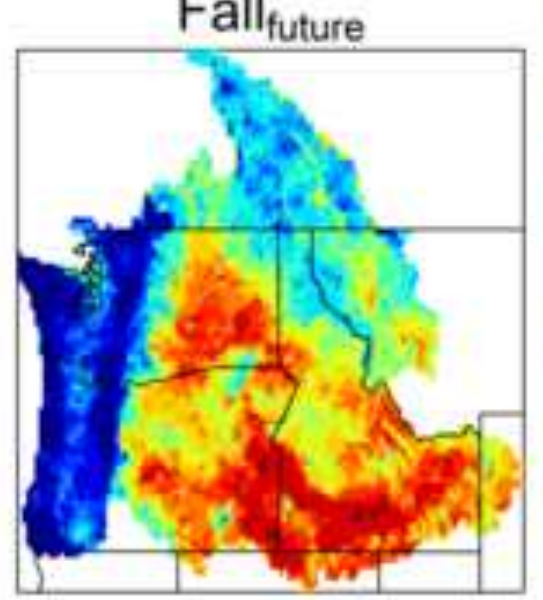

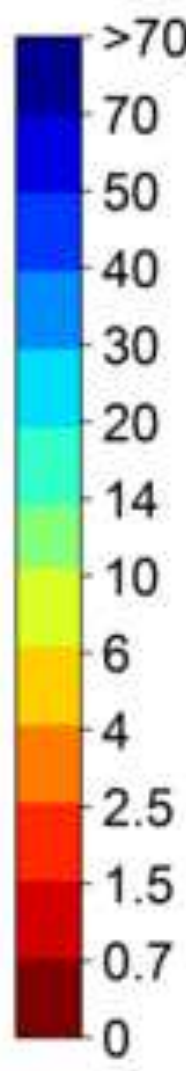



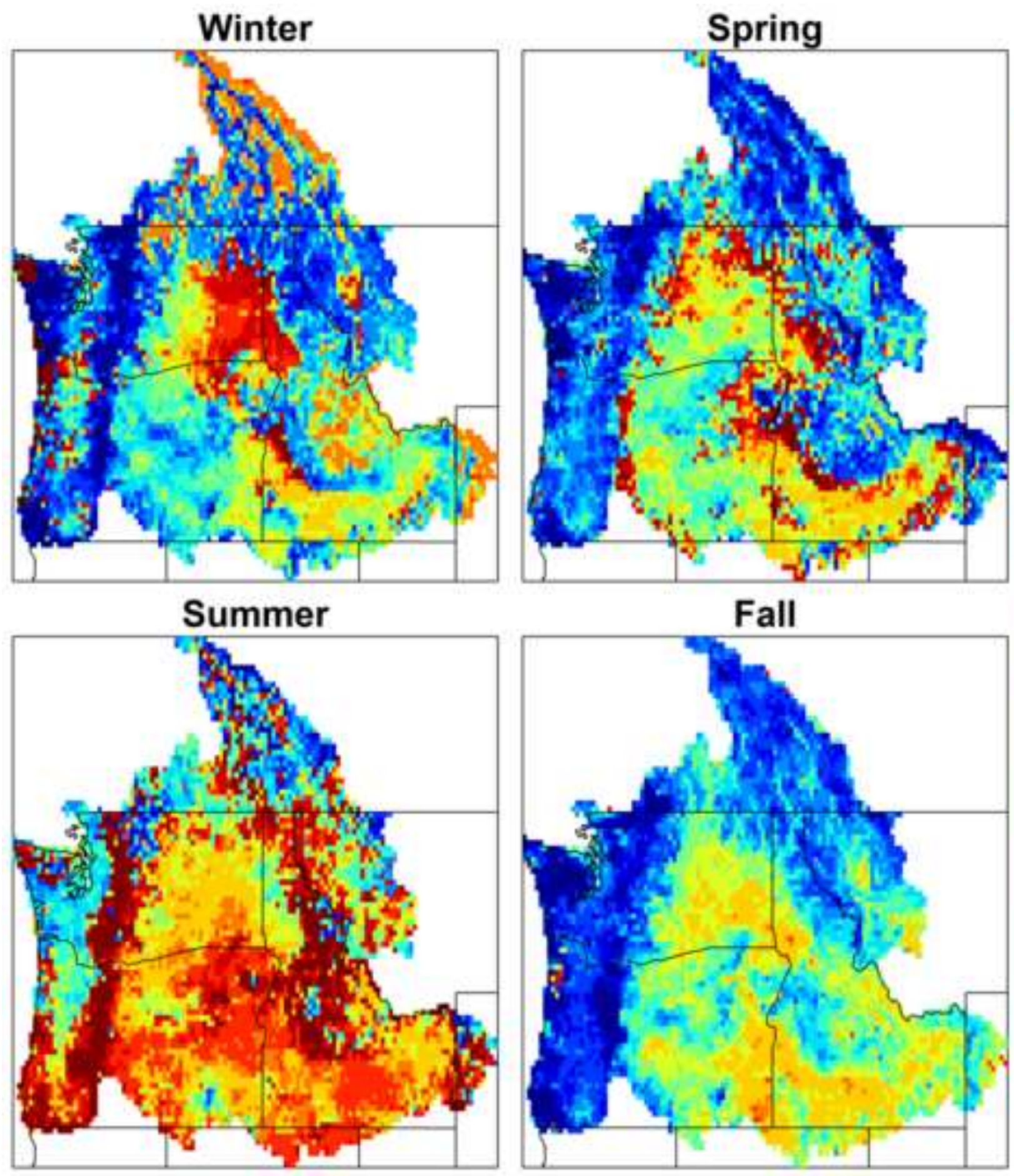

$>20$
-20
-12

Fall

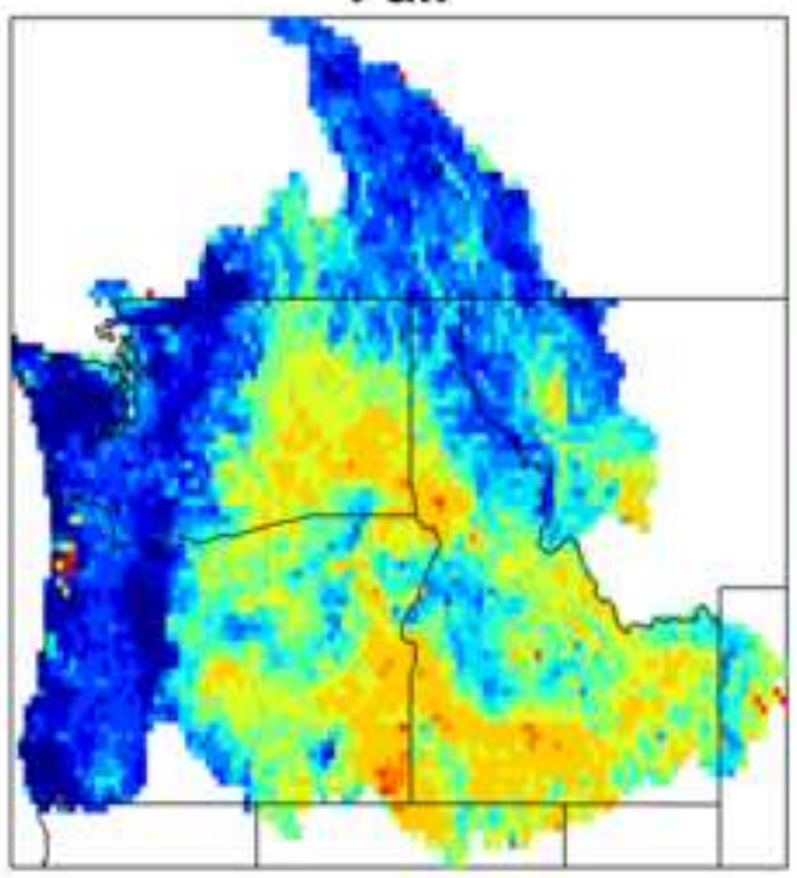

$-0.8$

0.4

0.1

$-0$

$-0.4$

$-3$

$<-3$ 
Figure 8
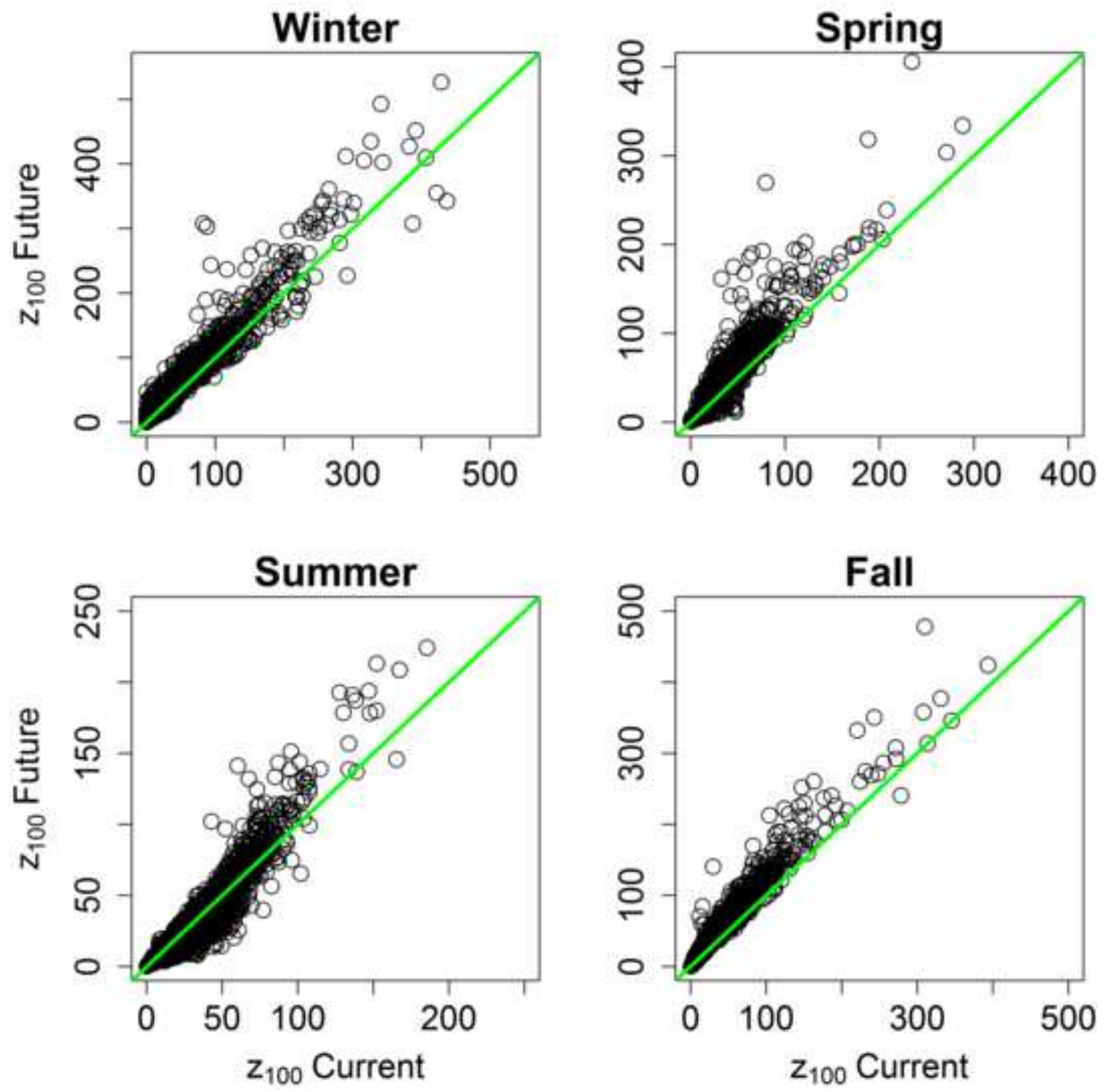
Table 1: Comparison of the mean absolute errors of the estimated 100-yr return level runoffs (mm) from BMA and the individual models.

\begin{tabular}{|l|r|r|r|r|r|r|r|r|r|}
\hline Seasons & \multicolumn{1}{l}{ BMA } & WRFG_cgcm3 & WRFG_ccsm & RCM3_cgcm3 & RCM3_gfdl & HRM3_hadcm3 & HRM3_gfdl & CRCM_cgcm3 CRCM_ccsm \\
\hline Winter & 2.84 & 3.26 & 3.17 & 3.37 & 3.27 & 7.98 & 3.03 & 3.8 & 2.78 \\
\hline Spring & 2.48 & 3.02 & 3.05 & 3.64 & 3.25 & 5.65 & 3.27 & 3.24 & 2.92 \\
\hline Summer & 1.99 & 2.16 & 2.03 & 2.68 & 2.5 & 3.48 & 2.65 & 2.64 & 2.42 \\
\hline Fall & 2.11 & 2.49 & 1.76 & 2.61 & 2.9 & 2.18 & 2.54 & 2.62 & 2.66 \\
\hline
\end{tabular}


Table 2: Calculated scaling factors based on the linear regression model of the future $(\mathrm{Y})$ and historical $(\mathrm{X})$ simulations.

\begin{tabular}{|l|l|l|l|}
\hline Season & Mean & $\mathbf{2 . 5 \%} \mathbf{C l}$ & $\mathbf{9 7 . 5 \%} \mathbf{C l}$ \\
\hline Winter & 1.112 & 1.1 & 1.118 \\
\hline Spring & 1.31 & 1.3 & 1.32 \\
\hline Summer & 1.051 & 1.044 & 1.058 \\
\hline Fall & 1.242 & 1.237 & 1.248 \\
\hline
\end{tabular}

